\title{
A Consciência Possível para Gestão do Conhecimento no Brasil
}

\section{The Possible Consciousness for the Management of Knowledge in Brazil}

\author{
La Posible Conciencia para la Gestión del \\ Conocimiento en Brasil
}

\author{
Isa Maria FREIRE 1 \\ Vania Maria Rodrigues Hermes de ARAUJO ${ }^{2}$ \\ Marco Antonio Almeida LLARENA ${ }^{3}$
}

Correspondência

Autor para correspondência: Isa Maria Freire

E-mail: isafreire@globo.com

ORCID: https://orcid.org/0000-0001-7603-1872

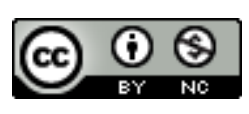

Submetido em: 01/10/2020

Aceito em: 21/12/2020

Publicado em: 31/12/2020

\footnotetext{
1 Doutora em Ciência da Informação pela Universidade Federal do Rio de Janeiro, Brazil. Docente permanente no Programa de Pós-Graduação em Ciência da Informação da Universidade Federal da Paraíba, Brasil.

2 Doutora em Comunicação e Cultura pela Universidade Federal do Rio de Janeiro, Brasil. Editora-Chefe da revista Pesquisa Brasileira em Ciência da Informação e Biblioteconomia PBCIB.

3 Docente EBTT do Instituto Federal de Educação, Ciência e Tecnologia da Paraíba- IFPB.
} 


\title{
RESUMO
}

Compartilha os primeiros resultados de pesquisa abordando a temática Gestão do conhecimento no campo da Ciência da Informação, no Brasil, na perspectiva da consciência possível, programada para realização em três etapas. Discorre sobre o conceito-chave da pesquisa e apresenta a rede conceitual que apoia seu desenvolvimento, e descreve sua metodologia, baseada no método indiciário, e procedimentos. Apresenta, como resultados da primeira etapa da pesquisa, quadros e gráficos sobre artigos publicados sobre a temática e indexados na Base de Dados em Ciência da Informação, no período 1999 a 2012, recuperados a partir de busca nos títulos, bem como dados sobre suas respectivas autorias. Foram recuperados 101 artigos, publicados em 19 periódicos da área de Ciência da Informação, a maioria descrita como "artigo científico" (33 artigos) e "artigo" (30 artigos), identificando 194 autores dos quais seis são os mais produtivos. Analisa os resultados obtidos, que sinalizam a comprovação da hipótese de trabalho, identificando período e eventos que representam a introdução da temática Gestão do conhecimento e sua crescente relevância no campo da Ciência da Informação, no Brasil.

Palavras-Chave: Gestão do conhecimento; Consciência possível; Rede conceitual; Método indiciário; Ciência da Informação - Brasil.

\begin{abstract}
It shares the first research results addressing the theme Knowledge Management in the field of Information Science, in Brazil, from the perspective of possible awareness, scheduled for realization in three stages. It discusses the key research concept and presents the conceptual network that supports its development, and describes its methodology, based on the indicator method, and procedures. It presents, as results of the first stage of the research, tables and graphs on articles published on the subject and indexed in the Information Science Database, from 1999 to 2012, retrieved from the search in the titles, as well as data on their respective. authorships. A total of 101 articles retrieved from 19 Information Science journals were retrieved, most of them described as "scientific articles" (33 articles) and "articles" (30 articles), identifying 194 authors of which five are the most productive. Analyzes the results obtained, which signal the confirmation of the working hypothesis, identifying the period and events that represent the introduction of the theme Knowledge Management and its growing relevance in the field of Information Science in Brazil.
\end{abstract}

Keywords: Knowledge management; Consciousness possible Conceptual network; Indicative method; Information Science - Brazil.

\section{RESUMEN}

Comparte los primeros resultados de la investigación que abordan el tema Gestión del conocimiento en el campo de las Ciencias de la Información, en Brasil, desde la perspectiva de la posible conciencia, programado para ser realizado en tres etapas. Discute el concepto clave de investigación y presenta la red conceptual que sustenta su desarrollo, y describe su metodología, basada en el método indicativo y los procedimientos. Presenta, como resultados de la primera etapa de la investigación, tablas y gráficos de los artículos publicados sobre el tema e indexados en la Base de Datos en Ciencias de la Información, de 1999 a 2012, recuperados de la búsqueda en los títulos, así como datos sobre sus respectivos paternidad literaria. Se recuperaron 101 artículos, publicados en 19 revistas del área de Ciencias de la Información, la mayoría calificados como "artículo científico" (33 artículos) y "artículo" (30 artículos), identificando 194 autores, seis de los cuales son los más productivos. Analiza los resultados obtenidos, que señalan la prueba de la hipótesis de trabajo, identificando el período y eventos que representan la introducción del tema Gestión del conocimiento y su creciente relevancia en el campo de las Ciencias de la Información en Brasil.

Palabras clave: Gestión del conocimiento; Posible conciencia; Red conceptual; Método indicativo; Ciencias de la información - Brasil. 


\section{INTRODUÇÃO}

Compartilhamos, na presente comunicação, os resultados preliminares de pesquisa abordando a Gestão do conhecimento no campo da Ciência da Informação, no Brasil, na perspectiva do conceito de consciência possível proposto por Lucien Goldmann (1970).

A ideia do trabalho surgiu de diálogo entre pesquisadores sobre a relevante produção e produtividade da pesquisa sobre a temática Gestão do conhecimento no campo no Brasil, quando foi percebida sua inserção a partir de determinado evento na história do campo da Ciência da Informação. Nesse sentido, percebeu-se que circunstâncias do desenvolvimento da temática na literatura brasileira da área apresentavam características de um epifenômeno de consciência possível, conforme descrito na seção Contexto desta comunicação.

A realização da pesquisa ocorre no âmbito da curiosidade que constitui característica dos pesquisadores trabalhadores científicos, e ainda não foi formalizado como ação reflexiva junto aos dispositivos do regime de informação acadêmico. Sem embargo, o entusiasmo de encontrar um problema interessante e pertinente no campo científico nos animou a iniciar o processo de investigação cujos primeiros resultados aqui apresentamos. Esse registro seguirá o curso natural da proposição de projetos de pesquisa aos Departamentos pertinentes, no âmbito das instituições acadêmicas às quais os autores estão vinculados. Ademais que a pesquisa tem previsão de continuidade, de modo a abranger variáveis indiretamente relacionadas ao fenômeno da consciência possível, mas diretamente relacionadas à produção científica sobre a temática 
Gestão do conhecimento, que apresenta um desenvolvimento crescente, no Brasil.

De modo que esperamos, com esta comunicação, abrir uma janela de oportunidade para aplicação de um modelo teórico a um fenômeno de informação, a partir de uma perspectiva sociológica, tecendo uma rede com fios conceituais interdisciplinares para apreender as circunstâncias, descrever e explicar como a temática Gestão do conhecimento veio a ocupar o lugar de destaque que, merecidamente, ocupa no campo da Ciência da Informação, no Brasil.

\section{A REDE CONCEITUAL}

Abordando a função da teoria na ciência, Bunge (1980, p. 160) aponta que, a rigor, as Ciências Sociais não oferecem "teorias" sobre seu objeto de estudo, sendo mais comum os quadros teóricos, ou "contexto", definidos como "conjunto de proposições referentes a um mesmo domínio [e] contendo certos conceitos (p.ex., os de classe social e anomia) que constituem um grupo homogêneo [...]". O contexto possuiria um grau de organização superior ao de um conjunto de proposições tomadas ao acaso, podendo ser negadas ou combinadas sem que desse processo resultem proposições estranhas ao próprio contexto.

[...] Um contexto serve, então, de matéria-prima para elaboração de teorias, uma vez que obteremos cada uma destas selecionando proposições do contexto e, em particular, guardando tão somente aquelas que constituam um conjunto coerente (não contraditório). (BUNGE, 1980, p.160)

O autor esclarece que o contexto em si contém a possibilidade da teoria, oferecendo tanto uma explicação para eventos e relações observados em um dado campo de pesquisa, quanto uma previsão 
para a ocorrência de eventos e relações ainda não observados, com base nos seus próprios princípios explanatórios. Afinal, embora represente um modo eficaz de explicar os fatos, toda teoria tem um caráter provisório, sendo aceita na medida de sua coerência semântica e do valor de verdade de suas predições.

Uma proposta nesse sentido foi apresentada por Wersig à Ciência da Informação, em conferência científica (Tampère, Finlândia, 1991), cujo texto final foi publicado em 1993. O autor sugere que o campo da Ciência da Informação poderia vir a tornarse "algum tipo de sistema de navegação conceitual" para abordagem dos problemas da informação, na sociedade contemporânea (WERSIG, 1993, p. 238), e caracteriza a Ciência da Informação como ciência pós-moderna, sugerindo que esse novo tipo de ciência não se restringiria a enunciados e conceitos, mas se ampliaria até a proposição de estratégias para solução de problemas. Pois, para Wersig (1993, p. 234), o campo da Ciência da Informação,

[...] exige o desenvolvimento de perspectivas que considerem a resolução de problemas internos ao campo científico e a estruturação do campo a partir dessa visão. Por outro lado, os problemas internos acontecem por causa de complexidades e contradições presentes nas situações sociais. Então, [nosso] campo teria, normalmente, uma estrutura que hoje abordaríamos como "caótica". O próximo passo seria estruturar essa realidade caótica, descobrindo seus "atratores estranhos" e suas contradições ou relações, para então contrastar a estrutura interna dos problemas do campo com as estruturas gerais. Por fim, estratégias têm que ser desenvolvidas para lidar com problemas em condições caóticas, usando os conceitos disponíveis, ou "atratores", para organizá-los. (Tradução livre)

Nesse sentido, o autor sugere para a Ciência da Informação uma estrutura teórica que considere menos a formulação de leis gerais e mais a de estratégias de ação, mediante uma abordagem de entrelaçamento de conceitos científicos, propondo um modelo de rede conceitual. Nesta perspectiva, conceitos fundamentais seriam semelhantes "a ímãs, ou 'atratores', atraindo os materiais [teóricos 
ou empíricos] para fora [dos seus respectivos campos científicos] e reestruturando-os dentro da estrutura científica da informação" (WERSIG, 1993, p. 238). Para o autor, o que se pode esperar é que este modelo seja "entretecido" por indivíduos ou equipes, oportunidade em que os fios soltos encontrados nos diferentes campos poderiam ser reunidos a outros fios conceituais numa rede.

Wersig (1993) desenvolve sua "rede" a partir da ideia de uma mudança real no papel do conhecimento para indivíduos, organizações e culturas. E, a partir desse modelo, tecemos, no presente trabalho nossa rede conceitual, usando o conceito de "consciência possível" como <atrator> para reunir fios conceituais no tear da Ciência da Informação, entrelaçando a trama em um contexto com o qual abordamos a emergência da "gestão do conhecimento" como temática no território da literatura da área, no Brasil (Figura 1).

Figura 1 - Rede conceitual na presente abordagem

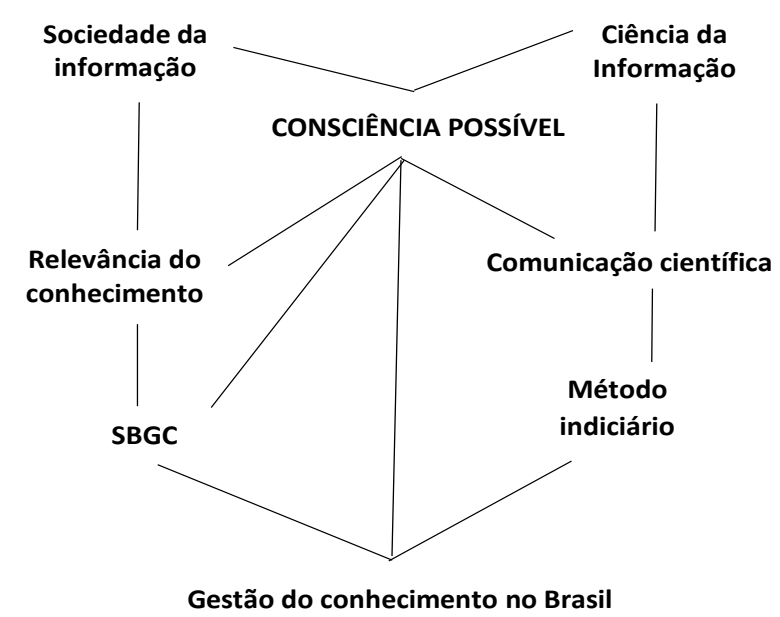

Fonte: Elaboração dos autores (2019).

Isso posto, descrevemos, a seguir, o atrator que organiza nossa rede conceitual. 


\subsection{A urdidura ${ }^{4}$ do texto}

Goldmann (1970, p. 39) propõe a aplicação do conceito de consciência possível à comunicação da informação, afirmando que se trata:

do fato de que, em uma [...] transmissão de informações, não existe apenas um homem ou aparelho emissor das informações e um mecanismo transmissor, mas, em alguma parte, existe também um ser humano que as recebe.

O autor propõe um modelo para abordar quatro situações em que ocorreriam problemas, ou barreiras, na comunicação da informação.

Uma informação pode não "passar" por faltarem ao receptor informações anteriores que o tornem apto a decodificar a mensagem e apreender o sentido que lhe atribuiu o emissor; em outra situação, elementos relacionados à estrutura psíquica do indivíduo e à sua biografia podem impedir a recepção e compreensão da informação, mas, tanto aqui quanto na situação anterior, podem ocorrer transformações individuais que venham a permitir o entendimento da mensagem pelo receptor. Uma terceira situação se refere ao coletivo: para receber e compreender a mensagem enviada, um grupo como tal teria de desaparecer ou transformar-se a ponto de perder suas características essenciais, pois haveria, em nível coletivo, uma consciência receptora que não é permeável a toda uma série de informações.

Por fim, um grupo social, em virtude de sua consciência real, resultante de seu passado e de acontecimentos que sobre ela agiram, pode resistir à passagem de certas informações. Um

\footnotetext{
4 "[...] 1 - Ato ou efeito de urdir (sentido próprio e figurado). 2 - Conjunto dos fios que se lançam ao comprimento do tear e por entre os quais se passa a trama ou fio. 3 - Trama; meada; enredo" (AURÉLIO, 2019). Disponível em: https://dicionariodoaurelio.com. Acesso em: 30 jun. 2019.
} 
exemplo, conforme Goldmann (1970), são pesquisadores que compartilham determinado paradigma e se recusam a tomar conhecimento de teorias que questionem sua abordagem; contudo, as dificuldades podem ser superadas por transformações pessoais que permitam aos pesquisadores reconhecer o valor de novas teorias, uma vez que essas transformações na consciência real não colocam em questão a existência do coletivo.

Mas, ao falar de expressão de uma consciência coletiva, Goldmann (1970) faz uma ressalva: um comportamento, ou uma obra, só se tornam expressão da consciência coletiva à medida que a estrutura que exprimem não seja particular ao seu autor, mas, sim, comum aos diferentes membros constituintes do grupo social. Nesse sentido,

Na perspectiva da consciência possível o problema não é saber o que pensa um grupo [um receptor de mensagens] mais quais sãos as mudanças suscetíveis de serem produzidas em sua consciência, sem que haja modificação na natureza essencial do grupo. (FREIRE, 2001, p. 71)

Contudo,

[...] Para O [cientista] a situação às vezes se apresenta diferente. Sua tarefa essencial é chegar ao conhecimento mais vasto e mais adequado da realidade. [Em certos casos, a] independência relativa do indivíduo em relação ao grupo permite-lhe [...] corrigir os limites duma visão por conhecimentos adequados, [...] ou ainda ampliar os limites da consciência real da classe, numa dada época, pelas possibilidades gerais dessa classe no conjunto do período histórico. (GOLDMANN, 1979, p.100)

E, conforme Silva (2019, p. 8) complementa,

[...] no contexto da Ciência da Informação, a consciência possível quer se desvincular de uma forma estática e esquemática da informação, procurando estabelecer vínculos com o estudo da vida social de uma comunidade e a relação entre transmissor e receptor de mensagens, isto é, as teias informacionais. 
Esta é a situação que abordamos na nossa proposta de pesquisa.

\subsection{O padrão que une}

A partir do nosso atrator conceitual, vamos buscar os indícios de uma visão de mundo em que a informação científica e tecnológica é considerada, em si mesma, como força produtiva e fator de transformação social. Buscaremos os indícios desta visão explicitada nos documentos do CIET, epifenômeno da consciência possível para Gestão do conhecimento no campo da Ciência da Informação, no Brasil. Nossa busca no território da literatura será realizada através do método indiciário, apoiados no axioma proposto por Rubem Alves (1994, p. 39) do cientista como "caçador do invisível".

Por milênios o homem foi caçador. Durante inúmeras
perseguições, ele aprendeu a reconstruir as formas e
movimentos das presas invisíveis pelas pegadas na lama, ramos
quebrados, [aprendeu] a farejar, registrar, interpretar e
classificar pistas infinitesimais [...] a fazer operações mentais
complexas com rapidez fulminante [...] Gerações e gerações de
caçadores enriqueceram e transmitiram esse patrimônio
cognoscitivo [...] (GINZBURG, 1989, p. 151)

O paradigma indiciário tem raízes muito antigas, que remontariam à própria evolução da humanidade. Nas palavras de Ginzburg (1989), ele se traduz em um saber de tipo venatório, caracterizado pela capacidade de, a partir de dados aparentemente irrelevantes, descrever uma realidade complexa que não seria cientificamente experimentável. Pode-se acrescentar que esses dados são sempre dispostos pelo observador [caçador] de tal modo que possam se traduzir em uma sequência narrativa cuja formulação mais simples poderia ser 'alguém passou por aqui': " O caçador teria sido o primeiro a 'narrar uma história', porque era o único capaz de ler, nas pistas mudas [... ] uma série coerente de eventos. 
'Decifrar' ou 'ler' as pistas dos animais são metáforas” (GINZBURG, 1989 , p. 152).

Criando sua própria metáfora, o autor compara as variáveis que compõem uma pesquisa desenvolvida sob o paradigma indiciário aos fios de um tapete. Definido o campo onde se realiza a investigação [o território], o pesquisador/tecelão busca os indícios de um padrão que [re]une as informações em uma interpretação que encontra seu significado no contexto teórico sustentado pela urdidura dos fios. A consistência da teia revelada no trabalho do pesquisador/tecelão é verificável "percorrendo-se o tapete com os olhos em várias direções" (GINZBURG, 1989, p. 170). O tapete seria o paradigma que, a cada vez que é usado, e conforme o contexto, denomina-se venatório, divinatório, indiciário ou semiótico.

[...] Trata-se de formas de saber tendencialmente mudas - no sentido de que [...] suas regras não se prestam a ser formalizadas nem ditas. Ninguém aprende o ofício de conhecedor ou de diagnosticador limitando-se a pôr em prática regras preexistentes. Nesse tipo de conhecimento entram em jogo [...] elementos imponderáveis: faro, golpe de vista, intuição. (GINZBURG, 1989, p. 177)

É o método que usamos quando buscamos indícios de um evento no território da literatura, pois, conforme Ginzburg (1989, p. 179), usando-se o termo "intuição" como sinônimo de processos racionais será possível resgatar antigos conceitos que fazem parte das origens da ciência, no Ocidente:

A antiga fisiognomonia árabe estava baseada na firasa: noção
complexa, que designava em geral a capacidade de passar
imediatamente do conhecido para o desconhecido, na base de
indícios. O termo, extraído do vocabulário dossufi, era usado
para designar tantos as intuições místicas quanto as formas de
discernimento e sagacidade [...].

Para o autor, essa "intuição" está arraigada nos sentidos, até mesmo superando os atributos biológicos, e seria difundida no mundo todo, sem limites geográficos, históricos, étnicos, sexuais ou 
de classe. É parte integrante do gênero humano e, nesse sentido, está muito distante de qualquer forma de privilégio social. Certamente por sua origem enraizada na fronteira indefinível entre natureza e cultura, o paradigma indiciário "pode se converter num instrumento para dissolver as névoas da ideologia que, cada vez mais, obscurecem uma estrutura social como a do capitalismo [Pois] se a realidade é opaca, existem zonas privilegiadas - sinais, indícios — que permitem decifrá-la (GINZBURG, 1989, p. 177).

Dessa forma, o paradigma indiciário poderia tornar-se um dos "fios" através dos quais o mistério da unidade subjacente à diversidade existente no mundo, objeto de todo conhecimento, pode adquirir um sentido. Como no caso que abordamos, na nossa pesquisa.

\subsection{Contexto}

No início de julho de 1997 foi aberto, no Centro Internacional para Educação, Trabalho e Transferência de Tecnologia (CIET) do Serviço Nacional de Aprendizagem Industrial (SENAI), o Seminário Gestão Estratégica do conhecimento, com apoio da Financiadora de Estudos e Projetos (FINEP), tendo como objetivo "mostrar como a gestão estratégica do conhecimento, baseada na administração inteligente da informação, pode contribuir para o aumento da capacidade de inovação das empresas e, consequentemente, tornálas mais competitivas" (CIET, 1997). ${ }^{5} \mathrm{O}$ evento se justificava pelos impactos decorrentes das transformações devidas aos impactos da

\footnotetext{
${ }^{5}$ Alguns dos palestrantes convidados: Stevan Dedijer, Doutor Honoris Causa pela Universidade de Lund, Suécia, criador do conceito de Inteligência Econômica; Ruth Stanat, presidente da SIS International Inc. e criadora do conceito de Redes de Inteligência corporativa; Julio Cubillo, coordenador do Programa de Gestão da Informação da Comissão Econômica para a América Latina (CEPAL); Henri Dou, Membro do Comitê Interministerial Francês de Informação Elaborada; François Jacobiak, Membro do Comitê Técnico Interministerial da França sobre Informação com Valor Agregado.
} 
"Economia globalizada, livre mercado, qualidade, competitividade, produção de conhecimento e oferta de informações, [...] que vêm provocando profundas e aceleradas mudanças nas sociedades" (CIET, 1997). A temática da Gestão do conhecimento chegava ao Brasil.

Dois anos depois, a abordagem chegava ao território da literatura brasileira da área de Ciência da Informação, através de artigo publicado no n.1 do v.4 da revista Perspectivas em Ciência da Informação (1999), e voltaria a aparecer no ano seguinte, em dois artigos publicados, respectivamente, na Revista de Biblioteconomia de Brasilia (hoje inativa) e na Revista ABC: Biblioteconomia em Santa Catarina. A temática, como tal, não era contemplada no território da literatura da Ciência da Informação no Brasil antes da realização do Seminário do CIET, mas, logo depois das primeiras publicações, quadruplicou o número de artigos, e continuou crescendo e se expandindo na área, como se pode observar no Quadro 1, a seguir:

Quadro 1: Gestão do conhecimento - Artigos indexados na Brapci ${ }^{6}$

\begin{tabular}{|c|c|}
\hline Período & $\begin{array}{c}\text { Qtde. } \\
\text { publicações }\end{array}$ \\
\hline 1996 a 2000 & 3 \\
\hline 2001 a 2004 & 13 \\
\hline 2005 a 2008 & 37 \\
\hline 2009 a 2012 & 48 \\
\hline 2013 a 2016 & 91 \\
\hline 2017 a 2019 & 122 \\
\hline \multicolumn{2}{|c|}{ Total 314} \\
\hline
\end{tabular}

Fonte: Dados da pesquisa, 2019.

\footnotetext{
${ }^{6}$ Base de Dados em Ciência da Informação. Disponível em: http://www.brapci.inf.br/. Acesso em: 30 jun. 2019.
} 
No início do século 21 foi criada a Sociedade Brasileira de Gestão do Conhecimento (SBGC), com o objetivo de promover "a integração entre academia, terceiro setor e organizações públicas e privadas interessadas em praticar, desenvolver e pesquisar o tema Gestão do Conhecimento" (SBGC, 2019)7. Desde 2002 a SBGC promove o KM Brasil, "maior evento de gestão do conhecimento da América Latina, e anualmente o Fórum Executivo com a participação de palestrantes com atuação relevante nacional e internacionalmente" (SBGC, 2019). E, em 2003, o Serviço Nacional de Aprendizagem Comercial traduziu e publicou, em São Paulo, o livro de Chun Wei Choo $(2003)^{8}$ que reúne conhecimento e informação de modo a facilitar a criação de significados e apoiar a tomada de decisão, nas organizações.

Desde 2002, a SBGC promove o KM Brasil, "maior evento de gestão do conhecimento da América Latina, e anualmente o Fórum Executivo com a participação de palestrantes com atuação relevante nacional e internacionalmente" (SBGC, 2019). ${ }^{9}$

$\mathrm{Na}$ pós-graduação, Duarte e colaboradores (2019) identificaram, entre os cursos na área de Ciência da Informação, desde os mais antigos aos mais recentes, oito mestrados profissionais, 16 mestrados acadêmicos e 12 doutorados que abordam a Gestão do conhecimento. Oferecidos por 21 universidades, 13 desses cursos de pós-graduação usam a palavra "conhecimento" em suas áreas de concentração e 12 a inserem em

\footnotetext{
${ }^{7}$ Disponível em: http://www.sbgc.org.br/sbgc.html. Acesso em: 7 jun. 2019.

${ }^{8}$ Professor e Diretor do Programa de Pós-Graduação em Informação da Universidade de Toronto.

9 A trajetória do GT-4 se inicia em 1994, com a ampla denominação de Administração/Gestão/Avaliação de Sistemas de Informação e Estudos de Usuários. Em 2007 passa a denominar-se Gestão da Informação e do Conhecimento nas Organizações, e de 2013 em diante adotou a denominação atual.
} 
seus eixos temáticos. A Gestão do Conhecimento chegou ao Brasil para ficar.

\section{TECENDO A TEIA DA REDE}

Nesta seção, apresentamos os procedimentos utilizados para tecer o contexto em torno da emergência da temática Gestão do conhecimento no campo da Ciência da Informação, no Brasil. Também são apresentados os primeiros dados coletados na Base de Dados em Ciência da Informação (Brapci), sobre a literatura publicada no período 1999-2012.

\subsection{Caçando no território da literatura}

Nossa pesquisa se caracteriza como exploratória, descritiva, documental e bibliográfica. Exploratória, pois ainda é necessário estabelecer uma maior familiaridade com o tema pesquisado, uma vez que a abordagem da consciência possível ainda é pouco conhecida; descritiva, por sua finalidade de descrever as características do fenômeno estudado, estabelecendo relações entre as variáveis identificadas; documental, porque utiliza dados e informações que ainda não foram abordadas científica ou analiticamente; e bibliográfica, porque se trata de revisão da literatura da área de Ciência da Informação pertinente à temática "Gestão do conhecimento" disponível na Brapci ${ }^{10}$.

A pesquisa no território da literatura está sendo conduzida através do método indiciário (GINZBURG, 1989), implementado

\footnotetext{
${ }^{10}$ A Base de Dados em Ciência da Informação indexa 80 periódicos da área e disponibiliza mais de 20 mil textos. Disponível em: http://www.brapci.inf.br/index.php/res/. Acesso em: 07 jun. 2019.
} 
mediante a técnica do brauseio, que, conforme Araújo (1994), consiste em uma atividade de busca a partir de uma necessidade ou interesse informacional. "Outra forma de descrever o processo de brausear seria equivalê-lo à 'arte de não saber o que se quer até que se o encontre'" (ARAÚJO, 1994, p. 108), o que, no âmbito da nossa pesquisa, significa procurar pistas sobre a emergência e consolidação da temática Gestão do conhecimento na área da Ciência da Informação, no Brasil. ${ }^{11}$

Considerando todos os campos semânticos de pesquisa oferecidos pela Brapci - título, palavras-chave, resumo - e as referências, o total indexado em "gestão do conhecimento", no período 1996-2019, alcançava 1.030 itens em 30 de junho de 2019.

Pesquisamos o termo "gestão do conhecimento" apenas na categoria "título", e iniciamos o período de busca em 1996, um ano antes do Seminário do CIET, adotando arbitrariamente o intervalo de quatro anos, conforme mostrado no Quadro 1. A seguir, no Quadro 2, apresentamos os resultados ano a ano, no intervalo de 1996 a 2012:

Quadro 2: Publicações na BRAPCI com Gestão do Conhecimento no título

\begin{tabular}{c|c|c|c|c|c|c|c|c|c|c|c|c|c|c|c|} 
Anos & 1999 & 2000 & 2001 & 2002 & 2003 & 2004 & 2005 & 2006 & 2007 & 2008 & 2009 & 2010 & 2011 & 2012 \\
\hline BRAPCl & 1 & 2 & 2 & 3 & 3 & 5 & 3 & 7 & 13 & 14 & 9 & 13 & 17 & 9 \\
\cline { 2 - 15 }
\end{tabular}

Fonte: Dados da pesquisa, 2019.

Considerando que iniciamos a pesquisa em abril de 2019, detalhamos e analisamos apenas e parcialmente os resultados do

\footnotetext{
${ }^{11} \mathrm{Na}$ continuidade da pesquisa, serão analisadas comunicações em eventos científicos da área, destacando-se o Encontro Nacional de Pesquisa da ANCIB.
} 
período 1996-2012, aqui apresentados. Esperamos concluir a coleta, tratamento e análise dos dados do período posterior nos próximos dois semestres (2019 e 2020), mapeando, inclusive, a rede social estabelecida entre os autores.

\subsection{Resultados preliminares}

Conforme os indícios observados, a Gestão do conhecimento se caracteriza por grande quantidade de autores em relação ao número de publicações: no período abordado nesta comunicação, 194 autores publicaram 101 textos em 19 periódicos indexados na Brapci. O quadro 3, a seguir, detalha essa dispersão de autoria, constatando-se poucas publicações de autoria única:

Quadro 3: Publicações por ano, coautoria e autoria única

\begin{tabular}{|c|c|c|c|}
\hline Ano & $\begin{array}{c}\text { Qtde. } \\
\text { Publicações }\end{array}$ & $\begin{array}{c}\text { Qtde. } \\
\text { Coautores }\end{array}$ & $\begin{array}{c}\text { Autoria } \\
\text { única* }\end{array}$ \\
\hline 1999 & 1 & 2 & - \\
\hline 2000 & 2 & 5 & - \\
\hline 2001 & 2 & 3 & 1 \\
\hline 2002 & 3 & 4 & 2 \\
\hline 2003 & 3 & 12 & - \\
\hline 2004 & 5 & 11 & 2 \\
\hline 2005 & 3 & 6 & - \\
\hline 2006 & 7 & 15 & 1 \\
\hline 2007 & 13 & 27 & 2 \\
\hline 2008 & 14 & 30 & 7 \\
\hline 2009 & 9 & 29 & 1 \\
\hline 2010 & 13 & 32 & 2 \\
\hline 2011 & 17 & 37 & 2 \\
\hline 2012 & 9 & 18 & 4 \\
\hline
\end{tabular}

Fonte: Dados da pesquisa, 2019

(*) Também incluídos em coautoria

O ano de 2002 assinala a maior relação entre publicações (três) e seus autores (quatro), sendo duas com autoria única, e em 2008 ocorreu a maior incidência de autorias únicas no período estudado. Dos 194 autores identificados no período abordado nesta comunicação, seis publicaram três artigos, sempre em co-autoria; 18 
publicaram dois artigos, sendo um desses em autoria única; 16 publicaram uma única vez em autoria única; os demais autores publicaram apenas um artigo e sempre em coautoria.

De modo que se observou o predomínio, no período abordado, de publicações em coautoria, mesmo para os autores mais produtivos, como se pode observar no quadro 3 , a seguir:

Quadro 3: Autores mais produtivos

\begin{tabular}{|l|c|c|}
\hline \multicolumn{1}{|c|}{ Autores } & $\begin{array}{c}\text { Qtde. } \\
\text { publicações }\end{array}$ & $\begin{array}{c}\text { Autoria } \\
\text { única }\end{array}$ \\
\hline DUARTE, E. N. & 6 & 1 \\
\hline TOMAÉL, M. I. & 5 & 1 \\
\hline BARBOSA, R. R. & 5 & 1 \\
\hline RADOS, G. J. V. & 5 & - \\
\hline STEIL, A. V. & 4 & - \\
\hline
\end{tabular}

Fonte: Dados da pesquisa, 2019.

$\left(^{*}\right)$ Dados: Inclui coautoria e autoria única.

O quadro 4, a seguir, mostra a distribuição das publicações de artigos nos 19 periódicos da área de Ciência da Informação indexados na Brapci e recuperados em nossa pesquisa:

Quadro 4: Publicação em Periódicos - 1999 a 2012

\begin{tabular}{|l|c|l|}
\hline \multicolumn{3}{|c|}{ PUBLICAÇõES } \\
\hline \multicolumn{1}{|c|}{ PERIÓDICo } & Qtd. & \multicolumn{1}{|c|}{ Ano (Qtd.) } \\
\hline Biblionline & 1 & $2011(1)$ \\
\hline $\begin{array}{l}\text { BIBLOS - Revista do Instituto de } \\
\text { Ciências Humanas e da Informação }\end{array}$ & 4 & $2008(2) ; 2009(1) ; 2012(1)$ \\
\hline Brazilian Journal of Information Science & 2 & $2009(1) ; 2011(1)$ \\
\hline Cadernos BAD & 1 & $2007(1)$ \\
\hline Ciência da Informação & 11 & $\begin{array}{l}2001(1) ; 2002(3) ; 2006(1) ; 2007(4) ; 2009 \\
(2)\end{array}$ \\
\hline
\end{tabular}




\begin{tabular}{|c|c|c|}
\hline DataGramaZero & 9 & $\begin{array}{l}2004(1) ; 2006(2) ; 2007(1) ; 2008(2) ; 2009 \\
(1) ; \\
2010(2)\end{array}$ \\
\hline Em Questão & 1 & $2010(1)$ \\
\hline $\begin{array}{l}\text { Encontros Bibli: Rev. Eletrônica de } \\
\text { Biblioteconomia e Ciência da } \\
\text { Informação }\end{array}$ & 3 & 2004(3) \\
\hline $\begin{array}{l}\text { InCID: Revista de Ciência da } \\
\text { Informação e Documentação }\end{array}$ & 2 & 2012(2) \\
\hline Informação \& Informação & 5 & 2007(1);2008(3);2011(1) \\
\hline Informação \& Sociedade: Estudos & 14 & $\begin{array}{l}2003(1) ; 2004(1) ; 2005(1) ; 2006(1) ; 2007 \\
(1) ; \\
2008(1) ; 2009(1) ; 2010(2) ; 2011(5)\end{array}$ \\
\hline Perspectivas em Ciência da Informação & 21 & $\begin{array}{l}1999(1) ; 2000(1) ; 2001(1) ; 2005(2) ; 2006 \\
(2) ; \\
2007(4) ; 2008(1) ; 2009(3) ; 2010(3) ; 2011 \\
(2) ; 2012(1)\end{array}$ \\
\hline $\begin{array}{l}\text { Perspectivas em Gestão \& } \\
\text { Conhecimento }\end{array}$ & 8 & 2011(4);2012(4) \\
\hline Ponto de Acesso & 5 & $2007(1) ; 2008(2) ; 2010(1) ; 2012(1)$ \\
\hline $\begin{array}{l}\text { Revista ACB: Biblioteconomia em Santa } \\
\text { Catarina }\end{array}$ & 4 & $2000(1) ; 2006(1) ; 2010(2)$ \\
\hline $\begin{array}{l}\text { Revista Brasileira de Biblioteconomia e } \\
\text { Documentação }\end{array}$ & 7 & 2008(2);2010(2);2011(3) \\
\hline Revista de Biblioteconomia de Brasília & 1 & $2000(1)$ \\
\hline $\begin{array}{l}\text { Revista Digital de Biblioteconomia \& } \\
\text { Ciência da Informação }\end{array}$ & 1 & $2011(1)$ \\
\hline $\begin{array}{l}\text { Revista Ibero-Americana de Ciência da } \\
\text { Informação }\end{array}$ & 1 & 2008(1) \\
\hline
\end{tabular}

Fonte: Dados da pesquisa, 2019.

No gráfico 1, a seguir, as publicações de artigos nos periódicos podem ser acompanhadas, destacando-se as revistas Perspectivas em Ciência da Informação (21), Informação \& Sociedade: Estudos (14), Ciência da Informação (11), DataGramaZero (9), Perspectivas 
em Gestão \& Conhecimento (8) e Revista Brasileira de Biblioteconomia e Documentação (7):

Gráfico 1: Publicações por Periódico 1996 - 2012

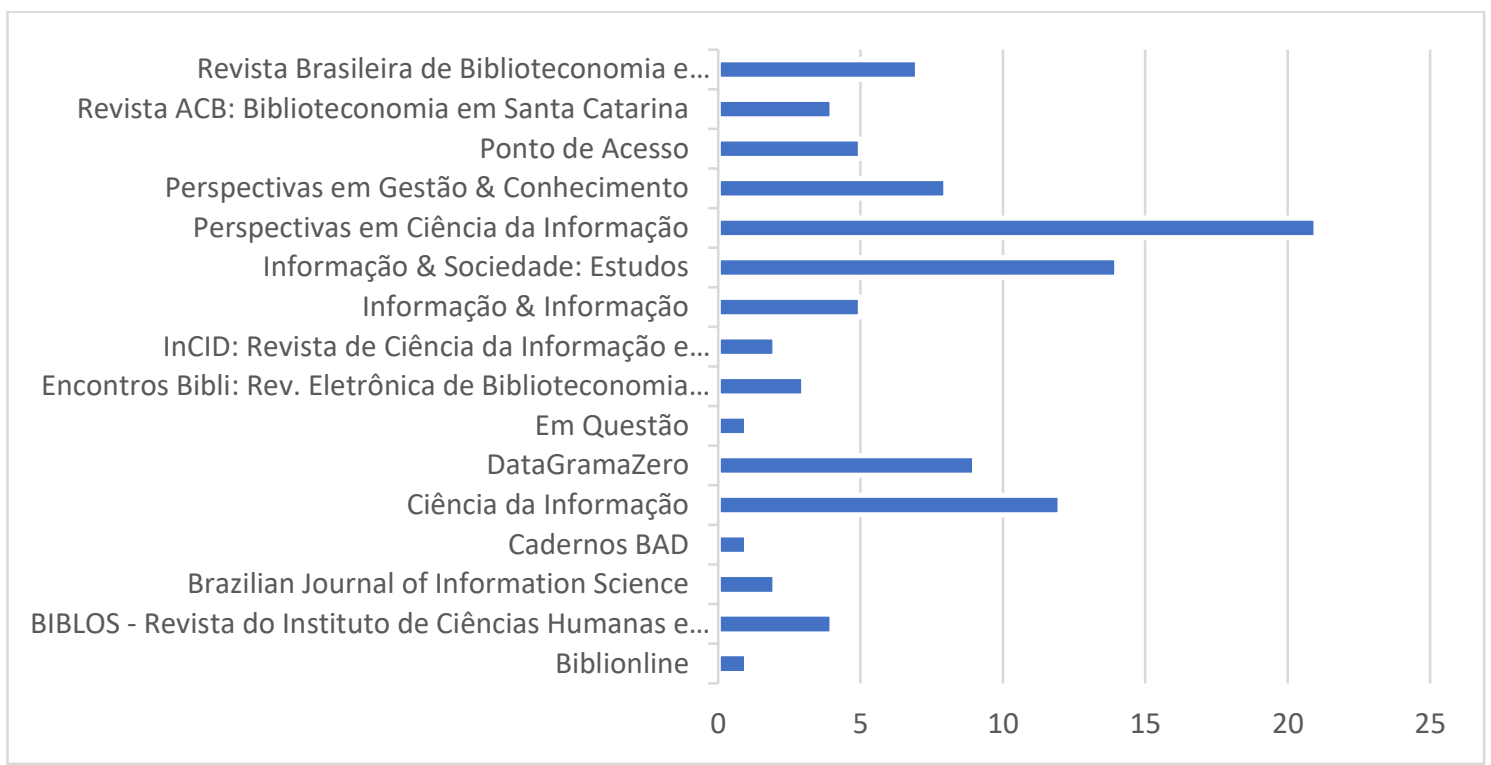

Fonte: Dados da pesquisa, 2019.

Os dados também podem ser observados através de uma nuvem de tags, como segue (Figura 1):

Figura 1: Nuvem de tags dos títulos de periódicos

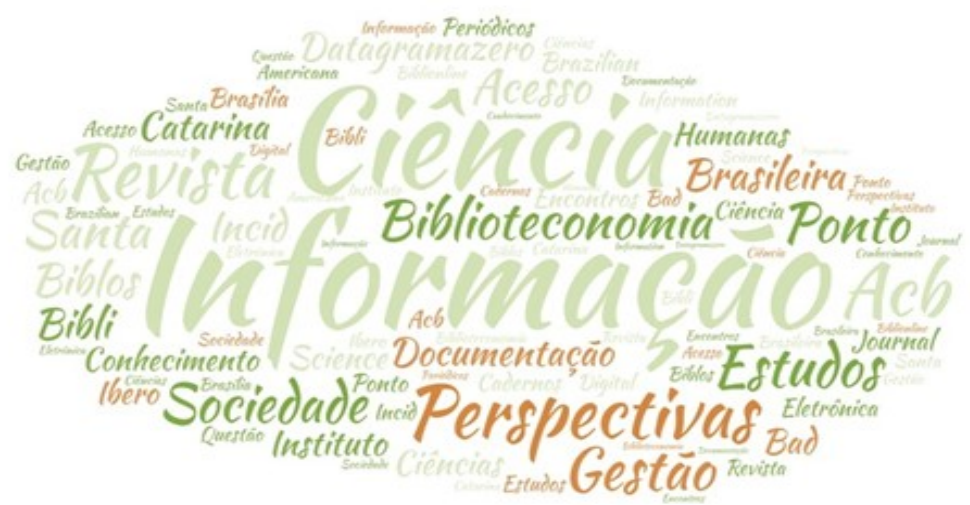

Fonte: Dados da pesquisa, 2019

Considerando a tipologia dos textos publicados, podemos inferir que a temática "Gestão do conhecimento" se tornou objeto de estudo relevante na área de Ciência da Informação, no Brasil, uma 
vez que a grande maioria das publicações são descritas, na Brapci, como "artigo científico" (33) e "artigo" (30), "artigo de revisão" (10), "relato de pesquisa" (10), "revisão de literatura" (6) e, por fim, "relato de experiência" (5) (Gráfico 2):

Gráfico 2: Tipologia dos textos publicados

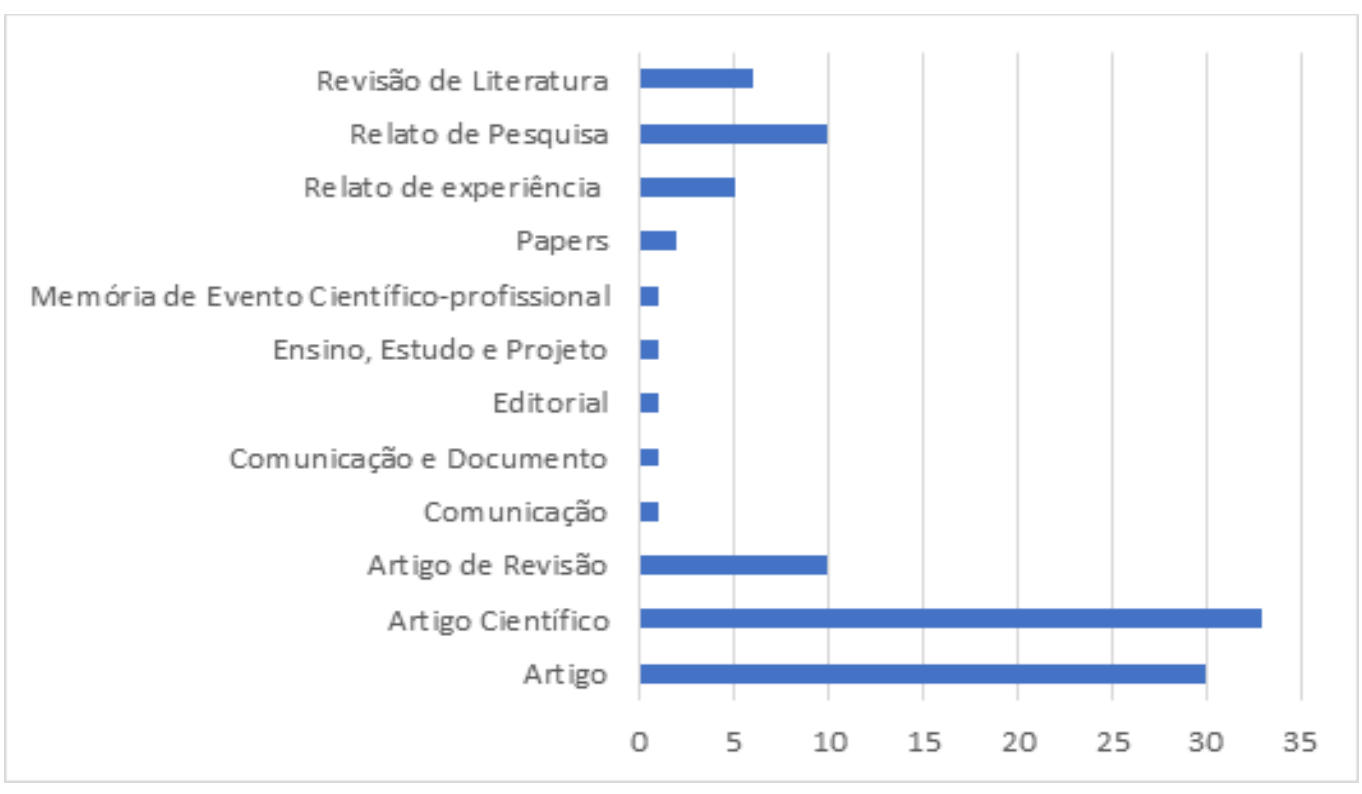

Fonte: Dados da pesquisa, 2019.

Os dados também podem ser observados através de uma nuvem de tags, como segue (Figura 2):

Figura 2: Nuvem de tags da tipologia dos textos publicados

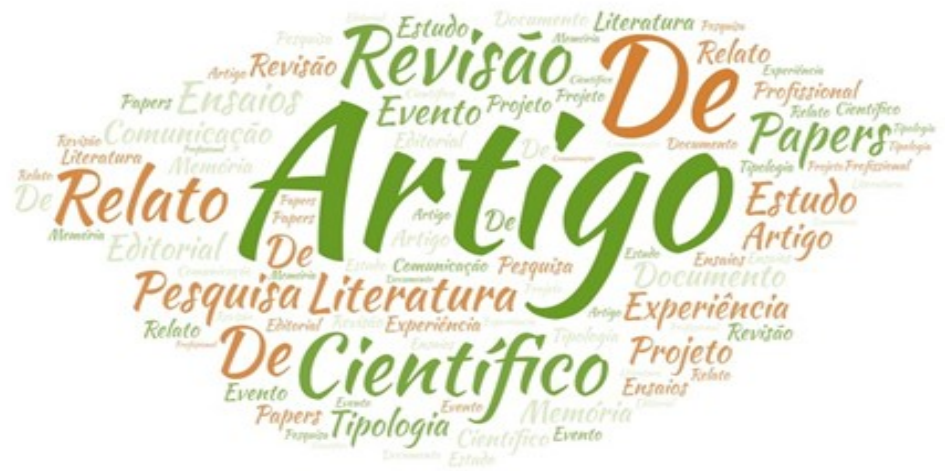

Fonte: Dados da pesquisa, 2019. 
De modo que é possível observar, nos indícios encontrados no território da literatura, no período 1999 a 2012, que a temática "Gestão do conhecimento" vem, gradativamente, ocupando um espaço relevante no campo da Ciência da Informação, no Brasil, a partir do evento fundador promovido pelo CIET, em 1997, aqui identificado como um evento de consciência possível, conforme proposto por Goldmann (1970) e aplicado por Freire (2001).

Algumas das questões que se colocam, no decorrer da continuidade da pesquisa, são:

- Dos autores identificados, quais estão vinculados à pósgraduação?

- Quais as relações entre os coautores: orientadores/orientandos, participantes de um mesmo Grupo de Pesquisa, participantes em um mesmo Programa de Pós-Graduação ou de Programas diferentes?

- Quais as palavras-chave mais utilizadas para descrever o conteúdo dos artigos?

- Considerando todo o período da pesquisa (1999 a 2020), quais as temáticas mais abordadas pelos autores?

Outras questões podem vir a surgir, a partir das discussões que a pesquisa possa suscitar nos fóruns onde for possível levar os resultados alcançados.

\section{CONSIDERAÇÕES FINAIS}

Como esperamos ter demonstrado nessa primeira aproximação do objeto de estudo, trata-se de uma temática que vem sendo abordada principalmente por núcleos de pesquisa, com destaque para os Programas de Pós-Graduação da Universidade Federal de Minas Gerais e da Paraíba, e com ocorrências também 
relevantes nas Universidades Estadual de Londrina e Estadual Paulista Júlio de Mesquita Filho.

$\mathrm{Na}$ área de Ciência da Informação, a Capes identifica 27 programas (dos quais 10 apresentam Gestão na área de concentração), e 40 cursos de pós-graduação, considerando doutorado, mestrado e mestrado profissional.

Entre estes, destacamos a distribuição regional dos cursos que abordam a Gestão da Informação e do Conhecimento, em sua área de concentração ou em suas linhas de pesquisa:: são oito na Região Nordeste (Sergipe, Bahia, Alagoas, Ceará [2], Paraíba, Rio Grande do Norte e Pernambuco); um na Região Norte (Pará); um no CentroOeste; quatro na Região Sul (Santa Catarina [2], Paraná e Rio Grande do Sul]; e 11 no Sudeste (Rio de Janeiro [4], São Paulo [3], Espírito Santo [2] e Minas Gerais [2]).

Com relação à produção científica, nesta etapa da pesquisa identificamos, no período de 1999 a 2012, a ocorrência de 194 publicações em 19 periódicos indexados na Brapci, onde se destaca a ocorrência de 63 "artigos" escritos por 194 autores, a grande maioria em coautoria.

O projeto terá continuidade nos próximos semestres, de modo a trazer, para acompanhamento e avaliação da comunidade científica, dados a partir de 2013 de forma mais circunstanciada e com uma análise que inclua as redes sociais às quais se vinculam os autores.

Contudo, e a nosso ver, a emergência da temática Gestão do conhecimento no campo da Ciência da Informação, no Brasil, já pode ser caracterizada como um fenômeno de consciência possível no campo da Ciência da Informação, no Brasil, como proposto por 
Goldmann (1970) às Ciências Sociais e aplicado por Freire (2001) à responsabilidade social da Ciência da Informação.

É essa trajetória que começamos a acompanhar, a partir do presente artigo.

\section{REFERÊNCIAS}

ALVES, R. Filosofia da ciência: Introdução ao jogo e as suas regras. São Paulo: Loyola, 1994.

ARAÚJO, V. M. R. H. Sistemas de recuperação da informação: nova abordagem teórico conceitual. 1994. 240 p. Tese (Doutorado Com. Cult.) - Escola de Comunicação, Universidade Federal do Rio de Janeiro, 1994.

BUNGE, M. Epistemologia: curso de atualização. 2. ed. São Paulo: T.A. Queiroz Ed., 1980.

CHOO, C. W. A organização do conhecimento: como as organizações usam a informação para criar significado, construir conhecimento e tomar decisões. São Paulo: Senac, 2003.

CENTRO INTERNACIONAL PARA EDUCAÇÃO, TRABALHO E TRANSFERÊNCIA DE TECNOLOGIA (CIET). Apresentação. Rio de Janeiro: SENAI-DN, 1997. Documento de arquivo.

DUARTE, E. N.; MONTEIRO, M. F.; FEITOZA, R. A. B.; COSTA, L. F. C.; LLARENA, R. A. S. Caracterização da disciplina gestão da informação e do conhecimento como eixo temático dos programas de pós-graduação em ciência da informação no Brasil. Pesquisa Brasileira em Ciência da Informação e Biblioteconomia, v. 14, n. 2, p. 206-216, 2019.

FREIRE, I. M. A responsabilidade social da ciência da informação e/ou $O$ olhar da consciência possível sobre o campo científico. 2001. Tese (Doutorado em Ciência da Informação) - Convênio CNPq/IBICT - UFRJ/ECO, Rio de Janeiro, 2001.

GINZBURG, C. Mitos, Emblemas e Sinais: morfologia e história. São Paulo: Cia das Letras, 1989. 
GOLDMANN, L. Importância do conceito de consciência possível para a informação. In: COLÓQUIOS FILOSÓFICOS DE ROYAUMONT. O conceito de informação na ciência contemporânea. Rio de Janeiro: Paz e Terra, 1970.

SILVA, L. E. F. Do "eu penso" da Ciência Moderna à consciência possível na Ciência da Informação: uma relação possível sob a égide da responsabilidade social da informação. Ciência da Informação em Revista, v. 6, n. 3, p. 3-14, set./dez. 2019.

SOCIEDADE BRASILEIRA DE GESTÃO DO CONHECIMENTO. Site institucional. Disponível em: http://www.sbgc.org.brl. Acesso em: 30 jun 2019.

WERSIG, G. Information science: the study of postmodern knowledge usage. Information Processing and Management, v. 29, n. 2, p. 229-239, Mar./Apr. 1993. 